\title{
Exploration on the Reform Direction of College English Teaching under the New Situation
}

\section{Ma Yufei}

Foreign Language Research Center, Shaanxi Academy of Governance, 710068

Keywords: Colleges and Universities; English Teaching; Reform

\begin{abstract}
With the development of Chinese economy and society, especially effected by globalization, Chinese demand for specialized English talents has increased both in quality and quantity. However, on the whole, there is still a huge gap between the current situation of English talent training in Chinese colleges and universities and the requirements of economic and social development. How to improve college English teaching reform under the new situation is not only an educational issue, but also a social issue. This paper gives a brief analysis of problems and causes existing in college English, and gives some reference suggestions for the reform of college English teaching.
\end{abstract}

\section{Introduction}

In recent years, Chinese economic and social development has been rapid, and the pattern of going out and introducing has affected various fields of national life. With the acceleration of the globalization trend, Chinese demand for English talents at all levels has shown a rapid growth. As the main place for cultivating professional talents for the social development and modernization of our country, colleges and universities shoulder a special and glorious historical mission.

After decades of development, college English teaching in China has achieved remarkable achievements in many aspects. While affirming the achievements, we must also see the shortcomings in the development of English teaching in colleges and universities in China. At present, in the important transitional stage of national development, the reform of college English teaching has become imperative. The voices of all walks of life to improve the quality of English talents in colleges and universities are becoming more and more urgent. We must comply with the requirements of the times, carefully examine our own deficiencies, and do a good job in the reform of college English teaching with a scientific and pragmatic attitude.

\section{The Main Problems in the Current College English Teaching}

At present, the main problems in college English teaching can be summarized into the following aspects.

\subsection{Outdated Teaching Methods}

Colleges and universities are the frontiers of accepting the trend of thought and information. However, there is always a huge conflict between the teaching of the various disciplines in Chinese colleges and universities and the frontier. Especially in the teaching methods, we are still basically using a single teaching mode. During the class, the teacher is in a dominant position, students are in a completely passive role and students have less interaction with the teacher. The teacher blindly teaches students through the classroom lecture and students are basically passively accepted. This blunt approach to education and teaching is a misunderstanding of the subject of English, and it is difficult to achieve the intended teaching objectives. This kind of education and teaching method is difficult to stimulate students' interest in learning, and in some aspects even limits students' ability to learn independently, which is the drawback of traditional education and teaching. Unfortunately, in today's increasingly advocating quality education, this outdated teaching method is still popular, and even is still in the mainstream in some schools' education and teaching. 


\subsection{The Overall Quality of Teacher Team is not High}

In education and teaching, teachers are the executors and planners of the curriculum. There is still a big gap between our college English teachers and the established requirements of higher English teaching, both in terms of academic composition and practical ability. First of all, many of college English teachers are graduates of English majors, rather than specialized educational talents with a teacher background. They only mastered the knowledge in terms of business ability, but they are still at the stage of exploration for the teaching and dissemination of knowledge. This has caused a lot of college English teachers to lack scientific teaching methods and means, and they always feel that they have nothing to do. Secondly, our teacher retraining and further education work is seriously lagging behind. Some 985 and 211 schools are regularly available in this area because of their unique advantages. Other institutions have many difficulties in terms of financial support and communication channels. Therefore, many teachers have never carried out knowledge renewal and capacity enhancement since they started their jobs. To a certain extent, this has limited the rapid improvement of teachers' literacy, and it has spurred the enthusiasm of teachers' work. They feel that their development space is limited, and they will inevitably have some slack and burnout in their hearts.

\subsection{The Assessment System is not Scientific}

Our college English assessment system is not tailor-made for college English learning, but it follows the traditional written examination and serves the exam-oriented education. Such an assessment system is neither reasonable nor scientific, and has been widely criticized. This kind of assessment system will have a very negative impact on students' English learning, and it is very unfavorable for students to adhere to English learning. It is easy for students to think that learn English is for exams, not for effective communication with others. The traditional assessment system is currently the most widely used in English exams, and it is also the most urgent need to change.

\subsection{Ignore the Application of New Media Technology}

I believe that new media is already familiar for many people, but it is not a simple matter to really understand the definition of new media. The so-called new media, in a certain sense, refers to the environment in which all things are media. In short, new media is more of an environment. The new media covers almost all digital media formats, including traditional networks, online media, mobile media, digital TV, newspapers and so on. After years of development, new media technologies have entered all aspects of our lives. However, in the English teaching of colleges and universities, the application of new media technology is not extensive. In the new media environment, students' initiative can be fully guaranteed and students are able to participate and learn cooperatively. The new media uses a networked platform as a learning tool. On this platform, it has rich learning resources, and students can make full use of the network to collect and organize learning materials. This mode breaks the traditional teacher-centered approach to education and teaching, and highlights the student's dominant position. At the same time, new media technologies are also conducive to teachers to update their ideas. Nowadays, more advanced education and teaching methods such as micro-course have been carried out in many disciplines. However, college English teaching has not adopted new media technologies, and it is clearly behind the construction of various disciplines.

\section{The Direction and Principles of College English Teaching Reform}

The reform of college English teaching is a systematic and comprehensive overall system. In a sense, the success or failure of college English teaching reform is not only related to the success or failure of improvement plan of college English talent training ability, but even affects the overall education and teaching reform process of colleges and universities. The direction of college English teaching reform must be guided by the issue of talent cultivation. In short, it is to take reform as a 
driving force, effectively improve students' English learning ability and practical application ability, and stimulate students' learning potential. The competition between countries today is, in the final analysis, the competition of talents and talent cultivation ability. In the reform of college English teaching, we should focus on improving students' comprehensive quality and innovative ability, and strive to align with the international advanced education and teaching achievements. Besides, we should also adhere to the educational philosophy of applying and transforming what you have learned into use, and using what you have learned to improve your knowledge.

\section{Measures of College English Teaching Reform}

Based on personal teaching experience, the author believes that our current college English teaching reform should mainly do the following work.

\subsection{Further Define the College English Orientation from Thought}

In the teaching of college English, we must clearly define the orientation of college English in order to have a clear and profound understanding of some problems in education and teaching. College English is a very important part of the university curriculum. College English not only allows students to learn knowledge, but also communication skills. Instrumentality is a prominent feature of college English. We cannot simply teach knowledge as the whole of college English teaching, but should focus most of our efforts on the cultivation of students' language ability. We must be good at guiding students out of the classroom to participate in social practice, find their own shortcomings, and then improve their self-learning ability. Only in this way can students have a comprehensive and clear understanding of English learning.

\subsection{Optimize Practice}

English practice has a special and extraordinary meaning for English learning. In the past, the practice of college English was mainly concentrated in the classroom, which was helpful for the improvement of students' practical ability. However, improvement was very limited due to the influence of the environment and conditions. Therefore, we must further optimize the student's practical environment. For example, in the school or department, we can get in touch with some companies to establish a practice base for both sides, so that students can truly get out of the campus and integrate into social practice. Previously, our college English teaching also neglected the cultivation of students' cultural literacy. The cultivation of cultural literacy can not be improved overnight, but improvement in practice is definitely a necessary measure to cultivate students' cultural literacy. Through practice, students will learn more about foreign cultures, diplomatic etiquette, and customs and historical details of different countries. These seemingly unrelated factors in English learning are an integral part of English learning and a driving force for improving students' English practice.

\subsection{Pay Attention to the Application of New Media Teaching Methods}

At present, with the rapid development of science and technology, teachers shoulder a special historical mission in cultivating students' innovative spirit. To cultivate students' innovative spirit, teachers themselves must be good at innovation. If teachers lack innovative thinking, then the discipline will lose its soul and motivation. The application of new media technology in education and teaching includes many cutting-edge scientific and technological achievements. To some extent, the English course in the new media environment is a new concept course. It is based on information and network technology and extends to various fields such as communication and multimedia. If teachers want to fully adapt to the teaching under the new media, they must integrate and improve their knowledge structure and broaden their horizons. This process is a process of self-improvement and self-remodeling of English teachers, and it is also a process of enhancing teachers' self-innovation ability. This will deeply influence the English teachers' understanding of the college English curriculum education and teaching in the new media environment at the ideological level. It is not only an extension of ideological understanding, but also an experience of 
practical action. The application of new media can effectively improve the display and interactivity of teaching methods in the teaching process, resulting in explosive growth of teaching content and capacity. In the new media environment, college English teachers can use modern technology to produce high-quality courseware with rich content, diverse forms and close to students' preferences. The communication between students and teachers is no longer limited to time and space, and communication can be carried out anytime and anywhere. Teachers don't have to use a piece of chalk or a blackboard like in the past. They can use tools such as computers, projectors, and network terminals to push pictures, texts, sounds, images and other information from time to time. College English courses in the new media environment have undergone tremendous changes in terms of information transfer structure, student understanding structure, classroom time integration, and teacher-student communication methods. Rich and interesting teaching methods and content have greatly stimulated students' interest in learning and led students to explore unknown areas. In the new media environment, knowledge is no longer a boring symbol, becoming a living individual. All-round stimulation of students' understanding of English can effectively improve students' learning efficiency and memory, thus fully optimizing classroom efficiency and improving teaching quality.

\subsection{Further Improve the Ability of College English Teachers}

A few years ago, there was a shortage of English teachers in colleges and universities in China due to the limitations of conditions. Many foreign language students began their coaching career directly after graduation. Many of them have accumulated education and teaching from scratch. Although this question has been improved to a certain extent in recent years, overall, the comprehensive ability of our college English teachers is not high. Therefore, we should open up a path for the improvement of teachers' abilities in a multi-channel and all-round way. And then teachers can improve in communication and learning, and have a clear and profound understanding of the development and reform of English teaching. Finally, overall level of the teacher team will be improved.

\section{References}

[1] Wang Shouren and Wang Haixiao. Investigation on the Current Situation and the Reform and Development Direction of College English Teaching in China [J]. Chinese Foreign Language, 2011, 05: 4-11.

[2] Yin Hesu and Yan Qigang. A Brief Talk on the Relationship between College English General Education and Special Purpose English Teaching--Discussion on the New Round of College English Teaching Reform and Development Direction [J]. Foreign Language Electrification Teaching, 2011, 01: 9-14.

[3] Shu Dingfang.The Goal and Direction of College English Teaching Reform [J]. Journal of Northeast Normal University (Philosophy and Social Sciences Edition), 2012, 01: 87-89.

[4] Kuang Wenbo. Introduction to New Media [M]. Beijing: China Renmin University Press, 2012.

[5] Zhou Hongchun and Liang Jing. The Reform of Teaching Methods in Colleges and Universities under the New Media Communication Environment [J]. China Electrification Education, 2013, (319): 107-109.

[6] Zou Xiaowei. Research on the Innovation of English Major Course Teaching Mode in the New Media Era [J]. Journal of Inner Mongolia Normal University (Educational Science Edition), 2014, 12: $113-114$.

[7] Li Xia. Analysis of the Application of New Media Resources in College English Teaching [J]. News Knowledge, 2012, 01: 107-108.

[8] Yu Jun. Study on the Cultivation of English Majors' Autonomous Learning Ability [J]. Foreign Language Teaching in Foreign Countries, 2006, (2). 
[9] Peng Yi. Cooperative Learning of College English in the New Media Environment [J]. Campus English, 2012 (11).

[10] Sha Zengyu. Discussion on the Application of New Technology and New Media in English Teaching [J]. Exam, 2012 (05). 